\title{
Numerical simulation of concrete slabs strengthened with PTFE sheets subjected to blast load
}

\author{
Rawy Youssef ${ }^{1,},{ }^{*}$ Walid Attia ${ }^{1}$, and Mohamed Laissy ${ }^{2}$ \\ ${ }^{1}$ Faculty of Engineering, Cairo University, Giza, Egypt \\ ${ }^{2}$ Faculty of Engineering, Prince Mugrin Bin Abdulaziz University, Medina, Saudi Arabia
}

\begin{abstract}
Due to the noticeable increase in bombing activities, the understanding of the structures response against blast loads has become one of the major concerns in structural engineering. This present study investigates the blast loading hazards that can take place in concrete slabs. Concrete slabs strengthened using PolyTetraFluoroEthylene (PTFE) are used to investigate the control of the hazards. The thickness of the slabs is $200 \mathrm{~mm}$. The models are exposed to a blast load equivalent to $20 \mathrm{Kg}$ of TNT explosives with a standoff distance equals to $500 \mathrm{~mm}$. The concrete slabs are strengthened using different thicknesses and different number of sheets. In order to investigate the effect of PTFE sheets, AUTODYN software is used to create the numerical models. Concrete is modelled using Lagrange solver while the air and TNT explosives are modelled using Euler solver. The results of the study show that PTFE sheets control concrete fragmentation and debris propagation. The use of PTFE can improve concrete resistance to one of the blast components because of its stability at high temperatures, thermal insulation, and resistance to weathering. PTFE has a wide working temperature range from $-100^{\circ} \mathrm{F}$ to $+400^{\circ} \mathrm{F}\left(-73^{\circ} \mathrm{C}\right.$ to $\left.204^{\circ} \mathrm{C}\right)$ in which its properties remain functional.
\end{abstract}

\section{Introduction}

An explosion can lead to many hazards that can jeopardize human safety. Some of those hazards are blast pressure, heat, structural collision, vibration, and fragments. Human tolerance to those hazards can vary widely [1]. Von Ramin et al. [2] studied the fragments distribution and energy from debris of a one way span masonry wall to predict the minimum safety ranges. Lin et al. [3] conducted a parametric study to investigate the responses of FRP-strengthened RC panels under blast loads. They found that increasing the thickness of the GFRP sheet decreases the maximum and residual deflections of RC panels. Tai et al. [4] studied the effect of meshing and steel reinforcement in concrete slabs. The study of the dynamic response of RC slabs showed that the mesh size is very sensitive to the shock wave propagation and should be as fine as possible. Also, the reinforcement ratio

* Corresponding author: rawy.adly@,yahoo.com 
in the concrete slab affects damage location. Weerheijm et al. [5] studied the failure of a one way concrete slab under internal explosion.

The objective of this research is to study the control of hazards in concrete slabs using PTFE sheets. A parametric study is conducted using AUTODYN to compare the behaviour of the slabs with different number and thickness of PTFE sheets.

PTFE $\left(\mathrm{C}_{2} \mathrm{~F}_{4}\right)_{\mathrm{n}}$ is an artificial highly crystalline fluoropolymer consisting of carbon and fluorine, it is best known commercially as Teflon. PTFE is chemically inert and resistant to attacks from corrosive chemicals. PTFE is highly dense and has a high melting temperature which makes it highly stable at high temperatures and has high impact strength $[6,7]$.

\subsection{Blast wave and debris propagation}

Figure 1 illustrates the idealization of a blast wave pressure-time history. The curve can be divided into two phases: positive and negative phases. At time $t_{A}$, detonation takes place. A sudden increase in pressure occurs, it is equal to $\left(P_{P}-P_{O}\right)$ and called overpressure. From $t_{A}$ to $t_{B}$, the positive phase represents the instantaneous rise of pressure and decrease of pressure to ambient condition. The negative phase starts at time $t_{B}$ and ends with the decay of the wave. The negative phase is longer than the positive phase and the pressure turns into a very small value of suction [8].

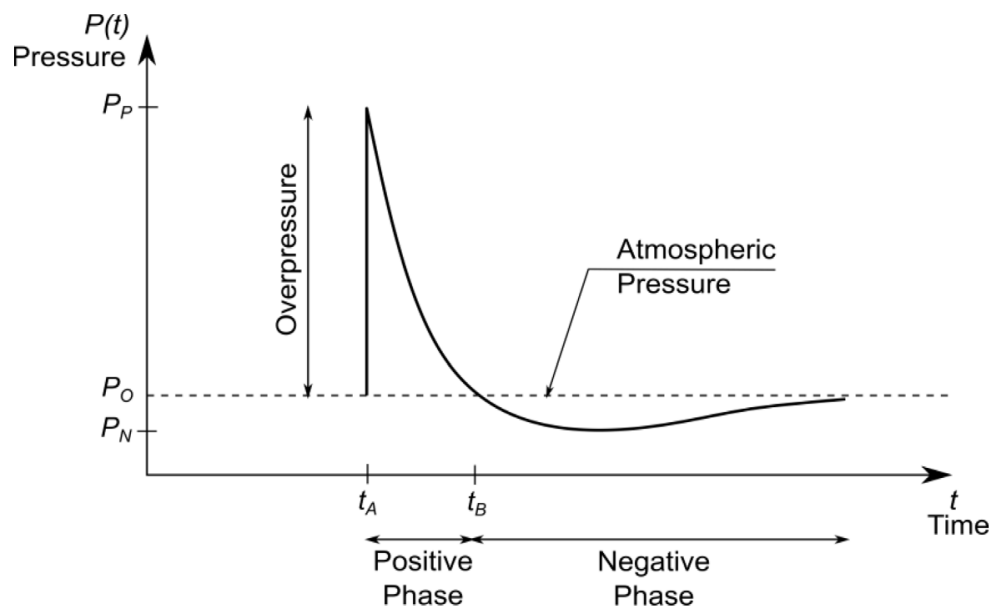

Fig. 1. Blast wave pressure-time history [8].

During an explosion, fragments may be formed from any object in the path of the blast wave. Fragments can travel for long distances thus increasing the blast radius and human injuries. The distance travelled by a fragment is affected by initial direction, size, shape, and explosion yield [8].

\subsection{Structural response to shock waves}

Analysis of structures under blast loads can be a complex process. In order to simplify this process, it is widely accepted to model the structure as a single degree of freedom SDOF.

Figure 2 illustrates the SDOF system for analysis. The structure is idealized as a lumped mass $M$ having a weightless spring with stiffness $K$ and an idealized triangular pulse as shown in Equation (1). Equation of motion for the un-damped SDOF is shown in Equation (2). Design for blast loads is affected mainly by the first cycle response, thus damping is neglected. $[1,9]$ 


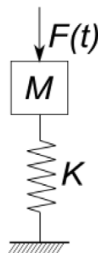

(a)

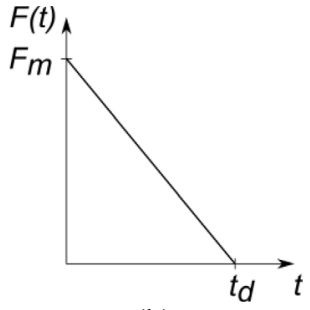

(b)

Fig. 2. (a) Un-damped SDOF system, (b) Blast load

$$
\begin{gathered}
F(t)=F_{m}\left(1-\frac{t}{t_{d}}\right) \\
M a+K y=F_{m}\left(1-\frac{t}{t_{d}}\right)
\end{gathered}
$$

Due to the dynamic analysis simplification, transformation factors for load, mass, and resistance are used to convert the required system for analysis into a SDOF.

\subsection{Concrete behaviour at high strain rates}

Concrete behaviour is different under dynamic and static loading. In dynamic loading, for the same strain value concrete reaches a higher value of stress. Strain rates for blast loads are $10^{11}$ times the static strain rates. According to Bischoff et al. the relative increase in concrete ultimate strength in uniaxial compression can reach a value of 2 [10] and according to Malvar et al. ultimate tensile strength can increase up to 7 times [11]. To account for this behaviour, codes of practice introduced the dynamic increase factor DIF which is defined as the ratio of the dynamic to static strength [1].

\section{Numerical simulation}

In order to conduct this study, accurate modelling of materials, loading, boundaries, meshing, and gauges are carried out. Approaches and techniques developed by AUTODYN software are used [12]. Setup for the analysis is $20 \mathrm{Kg}$ of TNT explosives placed at a standoff distance of $500 \mathrm{~mm}$ from the concrete slab as shown in Figure 3.

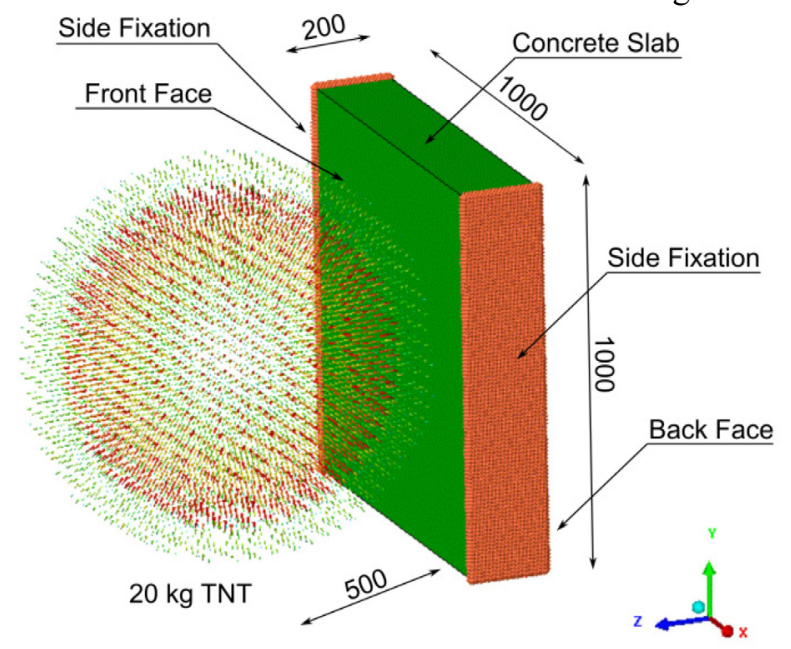

Fig. 3. Models setup. (dimensions in $\mathrm{mm}$ ) 


\subsection{Material description}

The materials used to simulate the concrete slab, PTFE sheets, and the surrounding medium are CONC-25MPA, TEFLON, and AIR respectively. The materials are taken from the AUTODYN materials library and adjusted to the conditions of the study. Equation of state, strength model, failure model, and properties for concrete, Teflon, and air are shown in Table 1.

Table 1. Materials models and properties.

\begin{tabular}{|c|c|c|c|c|c|c|c|}
\hline Material & $\begin{array}{l}\text { Equation } \\
\text { of State }\end{array}$ & $\begin{array}{c}\text { Strength } \\
\text { Model }\end{array}$ & $\begin{array}{c}\text { Failure } \\
\text { Model }\end{array}$ & $\begin{array}{l}\text { Erosion } \\
\text { Control }\end{array}$ & $\begin{array}{c}\text { Erosion } \\
\text { Strain }\end{array}$ & $\begin{array}{l}\text { Reference } \\
\text { Density } \\
\left(\mathrm{g} / \mathrm{cm}^{3}\right)\end{array}$ & $\begin{array}{c}\text { Shear } \\
\text { Modulus } \\
\text { (kPa) }\end{array}$ \\
\hline $\begin{array}{l}\text { CONC- } \\
\text { 25MPA }\end{array}$ & P alpha & $\begin{array}{c}\text { RHT } \\
\text { concrete }\end{array}$ & $\begin{array}{c}\text { RHT } \\
\text { concrete }\end{array}$ & $\begin{array}{l}\text { Instantaneous } \\
\text { geometric } \\
\text { strain }\end{array}$ & 0.7 & 2.5 & $1.67 \times 10^{7}$ \\
\hline TEFLON & Shock & $\begin{array}{l}\text { Von } \\
\text { Mises }\end{array}$ & $\begin{array}{l}\text { Hydro } \\
\text { (Pmin) }\end{array}$ & $\begin{array}{l}\text { Instantaneous } \\
\text { geometric } \\
\text { strain }\end{array}$ & 0.5 & 2.16 & $2.33 \times 10^{6}$ \\
\hline AIR & Ideal Gas & - & - & - & - & $1.225 \times 10^{-3}$ & - \\
\hline
\end{tabular}

\subsection{Geometry and mesh description}

For this study 24 models are carried out, all test specimens are 1000x1000x200 mm concrete slabs defined using Lagrange solver with mesh size 10x10x5 mm. PTFE sheets are modelled by filling the concrete slab part using the TEFLON material. The air and explosives are defined using Euler solver with mesh size 40x40x60 mm. All slabs are modelled as one way slabs using side fixation as boundary condition. Geometric details for models are illustrated in Figure 4 and Table 2. Figure 5 shows a sample from the models.

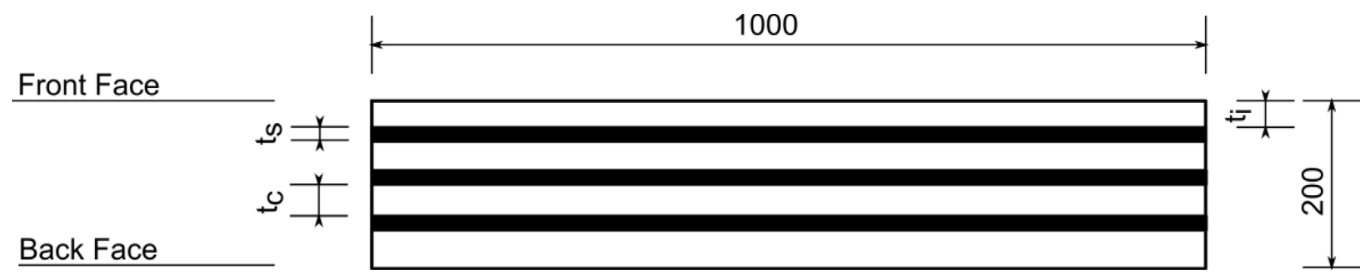

Fig. 4. Models schematic. (dimensions in $\mathrm{mm}$ )

Table 2. Sheets configurations.

\begin{tabular}{|c|c|c|c|c|c|c|c|c|c|}
\hline$\#$ & $\begin{array}{c}\boldsymbol{t s} \\
\mathbf{m m}\end{array}$ & $\boldsymbol{n s}$ & $\begin{array}{c}\boldsymbol{t c} \\
\mathbf{m m}\end{array}$ & $\begin{array}{c}\boldsymbol{t i} \\
\mathbf{m m}\end{array}$ & $\#$ & $\begin{array}{c}\boldsymbol{t s} \\
\mathbf{m m}\end{array}$ & $\boldsymbol{n s}$ & $\begin{array}{c}\boldsymbol{t c} \\
\mathbf{m m}\end{array}$ & $\begin{array}{c}\boldsymbol{t i} \\
\mathbf{m m}\end{array}$ \\
\hline S1 & - & - & - & - & $\mathrm{S} 13$ & 30 & 3 & 50 & 10 \\
\hline S2 & 5 & 1 & - & 10 & $\mathrm{~S} 14$ & 5 & 1 & - & 195 \\
\hline S3 & 10 & 1 & - & 10 & $\mathrm{~S} 15$ & 10 & 1 & - & 190 \\
\hline S4 & 20 & 1 & - & 10 & $\mathrm{~S} 16$ & 20 & 1 & - & 180 \\
\hline S5 & 30 & 1 & - & 10 & $\mathrm{~S} 17$ & 30 & 1 & - & 170 \\
\hline S6 & 5 & 2 & 50 & 10 & $\mathrm{~S} 18$ & 5 & 2 & 50 & 140 \\
\hline S7 & 10 & 2 & 50 & 10 & $\mathrm{~S} 19$ & 10 & 2 & 50 & 130 \\
\hline S8 & 20 & 2 & 50 & 10 & $\mathrm{~S} 20$ & 20 & 2 & 50 & 110 \\
\hline S9 & 30 & 2 & 50 & 10 & $\mathrm{~S} 21$ & 30 & 2 & 50 & 90 \\
\hline S10 & 5 & 3 & 50 & 10 & $\mathrm{~S} 22$ & 5 & 3 & 50 & 85 \\
\hline S11 & 10 & 3 & 50 & 10 & $\mathrm{~S} 23$ & 10 & 3 & 50 & 70 \\
\hline S12 & 20 & 3 & 50 & 10 & $\mathrm{~S} 24$ & 20 & 3 & 50 & 40 \\
\hline
\end{tabular}


ts is the PTFE sheet thickness in mm.

$n s \quad$ is the number of PTFE sheets.

tc is the concrete thickness between PTFE sheets in $\mathrm{mm}$.

$t i \quad$ is the initial concrete thickness at the front face in $\mathrm{mm}$.

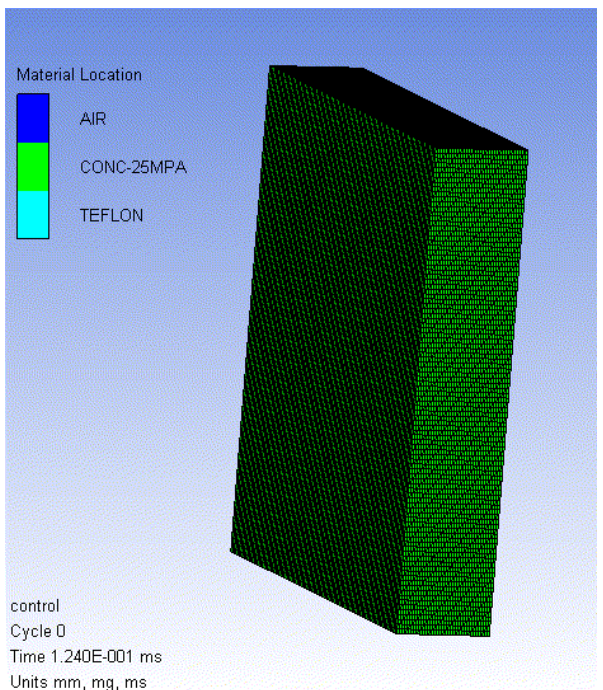

(a)

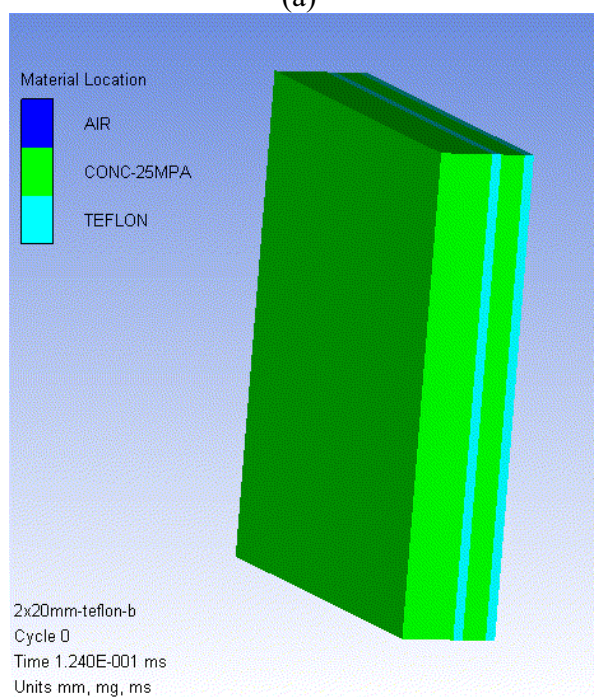

(c)

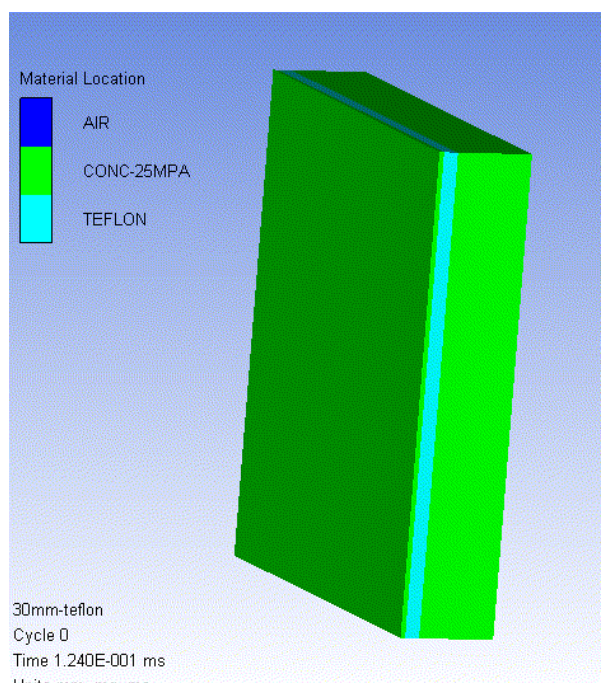

(b)

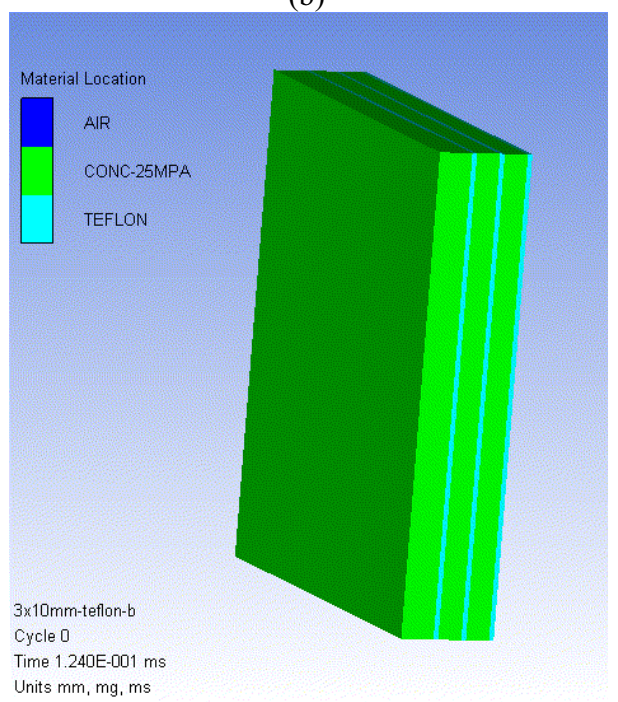

(d)

Fig. 5. Sample of models (a) S1 model, no PTFE sheets and showing the mesh grid, (b) S5 model, $30 \mathrm{~mm}$ sheet at the front face, (c) S20 model, two $20 \mathrm{~mm}$ sheets at the back face, and (d) S23 model, three $10 \mathrm{~mm}$ sheets at the back face.

\subsection{Explosion Simulation Validation}

In order to validate the TNT charge used in the simulation, overpressure from manual calculations and the simulation are compared. Overpressure is calculated manually from Kinney and Graham [8] overpressure formulation described in Equation (3) and UFC 3- 
340-02 technical manual [1]. Scaled distance of the equivalent TNT explosives is calculated using Equation (4).

$$
\begin{gathered}
P_{S O}=P_{O} \frac{808\left[1+\left(\frac{Z}{4.5}\right)^{2}\right]}{\sqrt{\left[1+\left(\frac{Z}{0.048}\right)^{2}\right]\left[1+\left(\frac{Z}{0.32}\right)^{2}\right]\left[1+\left(\frac{Z}{1.35}\right)^{2}\right]}} \\
Z=\frac{R}{\sqrt[3]{W}}
\end{gathered}
$$

$R \quad$ is the distance between the centre of the explosion and the gauge in $\mathrm{m}$

$W \quad$ is the weight of the TNT explosives in $\mathrm{kg}$.

$Z \quad$ is the scaled distance in $\mathrm{m}$.

$P_{S O}$ is the overpressure in $\mathrm{kPa}$.

$P_{O}$ is the ambient pressure equal to $101.325 \mathrm{kPa}$.

Pressure-time history for the $20 \mathrm{~kg}$ explosives in the AUTODYN simulation is illustrated in Figure 6. Overpressure is taken as the peak value from the pressure-time history and compared with manual calculations in Table 3. Comparison shows that AUTODYN overpressure value is relatively close to the overpressure values manually calculated.

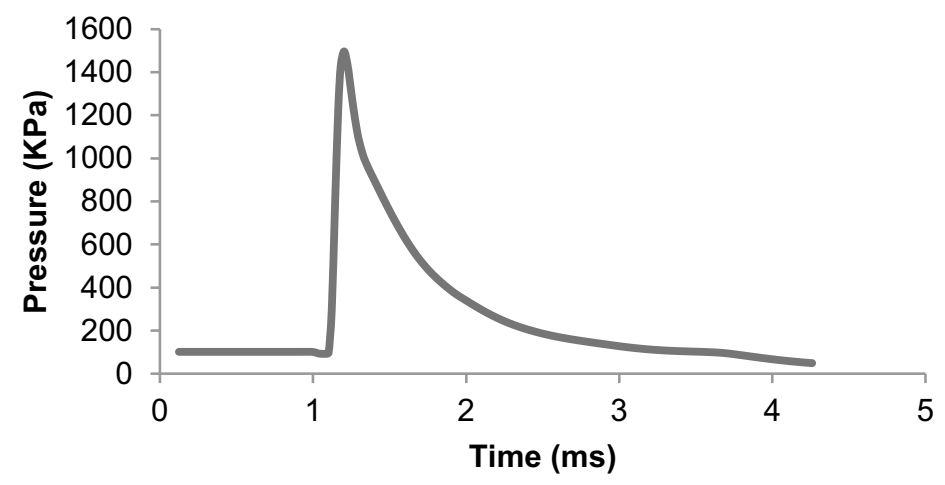

Fig. 6. Pressure-time history from the AUTODYN Model for $\mathrm{R}=2.5 \mathrm{~m}$ and $\mathrm{W}=20 \mathrm{~kg}$.

Table 3. Overpressure Calculations.

\begin{tabular}{|c|c|c|c|c|c|}
\hline$R$ & $W$ & $\boldsymbol{Z}$ & \multicolumn{3}{|c|}{ Pso (kPa) } \\
\cline { 4 - 6 } $\mathbf{m}$ & $\mathbf{~ k g}$ & $\mathbf{m} / \mathbf{k g}^{\mathbf{1 / 3}}$ & Kinney \& Graham & UFC 3-340-02 & AUTODYN Model \\
\hline 2.5 & 20 & 0.921 & 1204 & 1380 & 1497 \\
\hline
\end{tabular}

\section{Results}

From this study, we can notice that the maximum deflection is found in slabs at midspan. Concrete experiences mostly flexural failure at midspan and a combination of flexural and shear failure at the side fixation. The use of PTFE sheets reduces the debris and fragmentation up to $90 \%$, thus decreasing the blast radius and human injuries. Table 4 shows results for maximum fragment propagation $(F P)$, approximate fragmentation percentage $(F)$, and pressure behind the slabs $(P)$. Figures 7 to 13 show the numerical models. 
Table 4. Numerical simulation results.

\begin{tabular}{|c|c|c|c|c|c|c|c|}
\hline$\#$ & $\begin{array}{c}F P \\
\mathbf{m m}\end{array}$ & $\begin{array}{c}\boldsymbol{F} \\
\mathbf{\%}\end{array}$ & $\begin{array}{c}\boldsymbol{P} \\
\mathbf{k P a}\end{array}$ & $\#$ & $\begin{array}{c}\boldsymbol{F P} \\
\mathbf{m m}\end{array}$ & $\begin{array}{c}\boldsymbol{F} \\
\mathbf{\%}\end{array}$ & $\begin{array}{c}\boldsymbol{P} \\
\mathbf{k P a}\end{array}$ \\
\hline S1 & 768.35 & 100 & 106.69 & $\mathrm{~S} 13$ & 143.22 & 1 & 105.83 \\
\hline S2 & 838.37 & 100 & 106.43 & $\mathrm{~S} 14$ & 604.48 & 75 & 106.71 \\
\hline S3 & 844.84 & 100 & 106.44 & $\mathrm{~S} 15$ & 686.92 & 65 & 106.65 \\
\hline S4 & 785.5 & 100 & 106.65 & $\mathrm{~S} 16$ & 552.8 & 60 & 106.42 \\
\hline S5 & 873.58 & 100 & 106.85 & $\mathrm{~S} 17$ & 569.46 & 50 & 106.24 \\
\hline S6 & 757.04 & 65 & 106.51 & $\mathrm{~S} 18$ & 667.2 & 80 & 106.62 \\
\hline S7 & 911.03 & 60 & 106.41 & $\mathrm{~S} 19$ & 576.49 & 70 & 106.39 \\
\hline S8 & 685.73 & 45.5 & 106.47 & $\mathrm{~S} 20$ & 296.81 & 10 & 106.04 \\
\hline S9 & 705.5 & 40 & 106.22 & $\mathrm{~S} 21$ & 168.39 & 5 & 105.94 \\
\hline S10 & 694.46 & 37.5 & 106.43 & $\mathrm{~S} 22$ & 635.32 & 60 & 106.53 \\
\hline S11 & 920.69 & 30 & 106.34 & $\mathrm{~S} 23$ & 378.18 & 5 & 106.28 \\
\hline S12 & 957.92 & 15 & 106.22 & $\mathrm{~S} 24$ & 175.3 & 1 & 106.07 \\
\hline
\end{tabular}

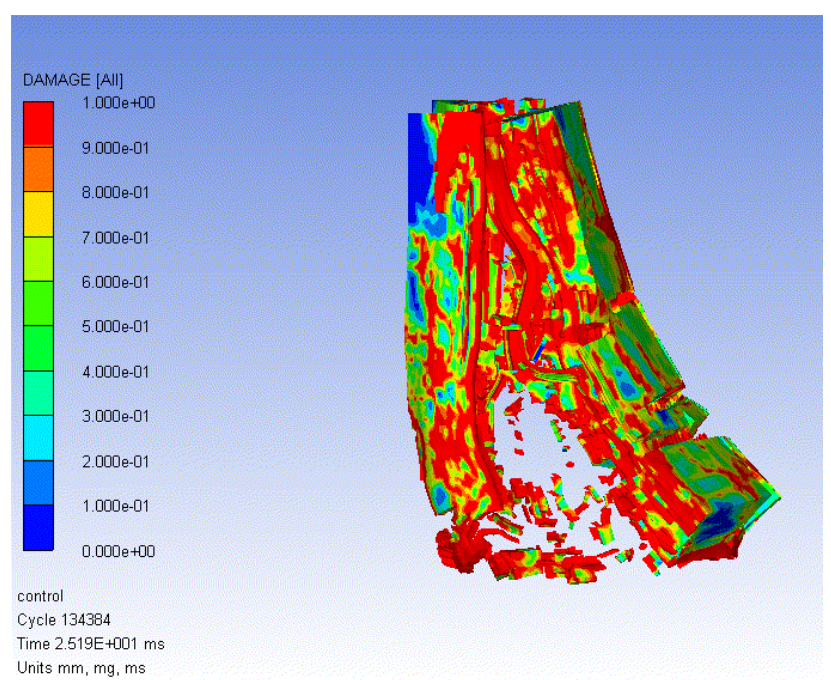

Fig. 7. S1 model, no PTFE sheets and showing the damage.

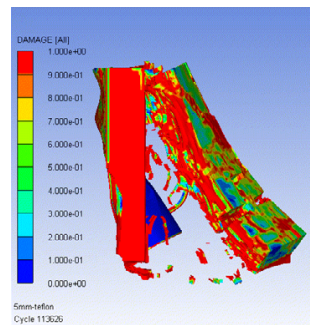

(a)

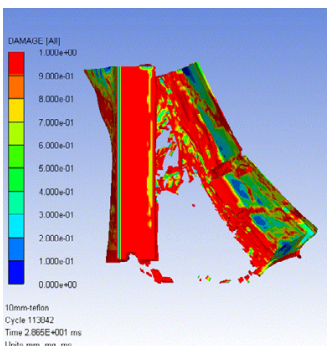

(b)

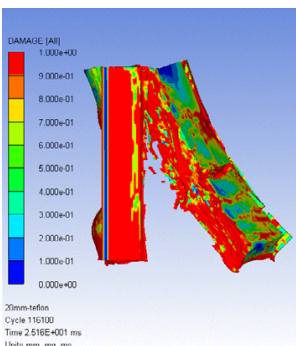

(c)

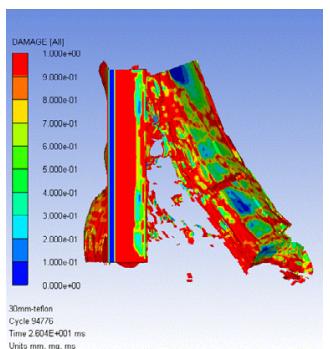

(d)

Fig. 8. One PTFE sheet at the front face models showing the damage, (a) S2 model, (b) S3 model, (c) S4 model, (d) S5 model. 


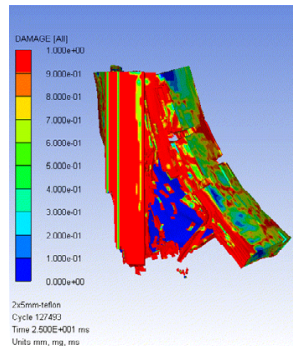

(a)

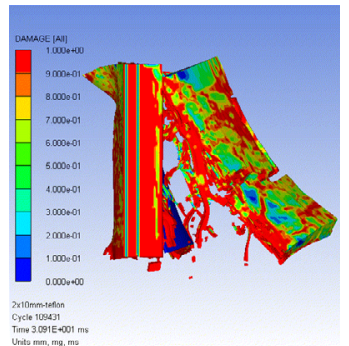

(b)

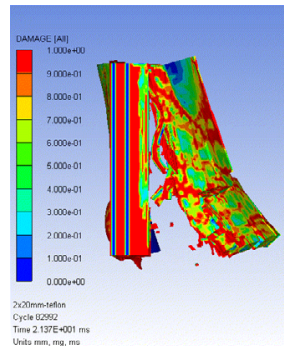

(c)

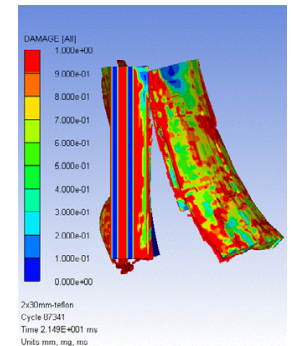

(d)

Fig. 9. Two PTFE sheets at the front face models showing the damage, (a) S6 model, (b) S7 model, (c) S8 model, (d) S9 model.

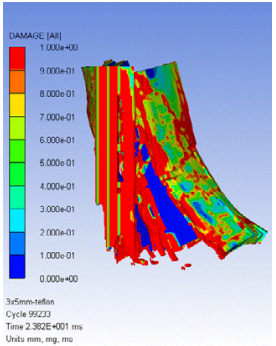

(a)

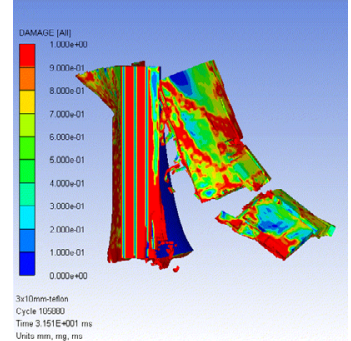

(b)

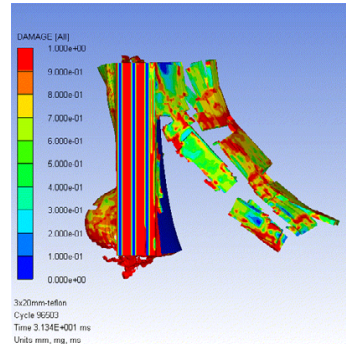

(c)

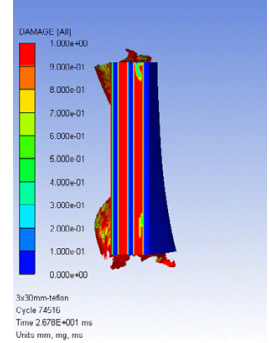

(d)

Fig. 10. Three PTFE sheets at the front face models showing the damage, (a) S10 model, (b) S11 model, (c) S12 model, (d) S13 model.

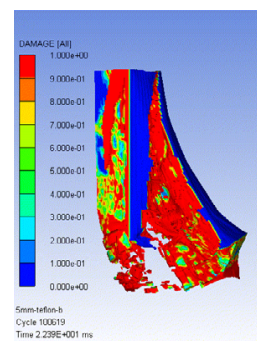

(a)

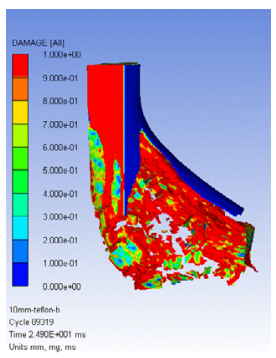

(b)

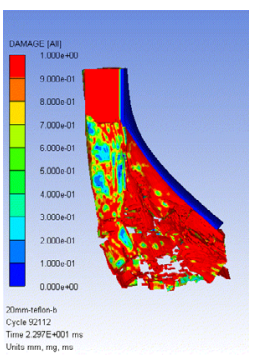

(c)

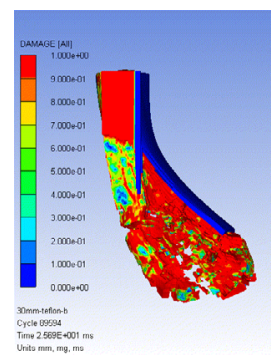

(d)

Fig. 11. One PTFE sheet at the back face models showing the damage, (a) S14 model, (b) S15 model, (c) S16 model, (d) S17 model.

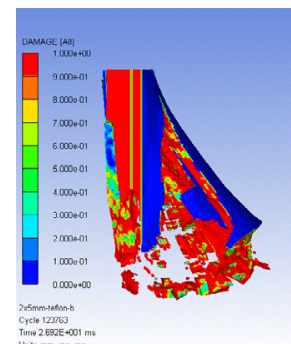

(a)

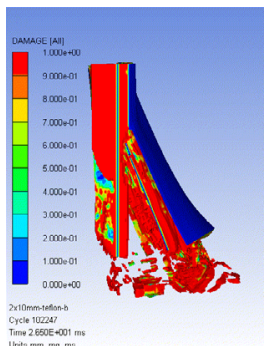

(b)

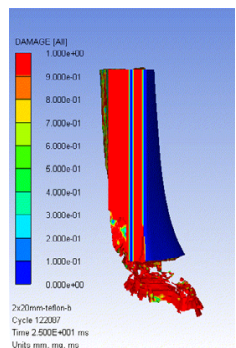

(c)

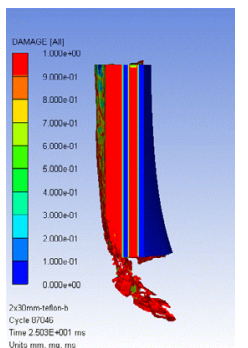

(d)

Fig. 12. Two PTFE sheets at the back face models showing the damage, (a) S18 model, (b) S19 model, (c) S20 model, (d) S21 model. 


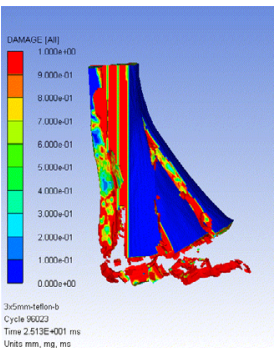

(a)

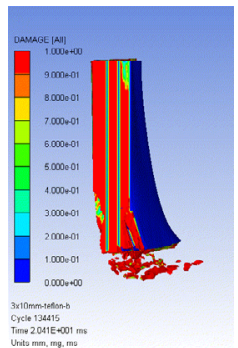

(b)

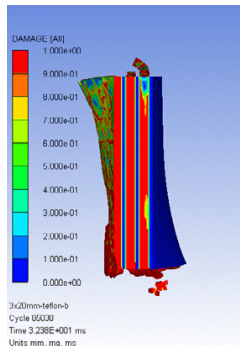

(c)

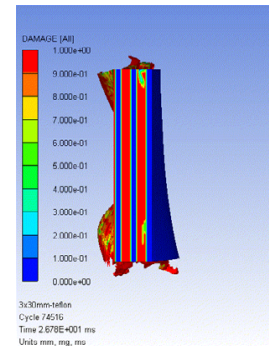

(d)

Fig. 13. Three PTFE sheets at the back face models showing the damage, (a) S22 model, (b) S23 model, (c) S24 model, (d) S13 model.

\section{Conclusion}

From this study, we can conclude the following:

- Numerical simulation of the blast wave propagation in ANSYS AUTODYN is satisfactory.

- Optimum placement of PTFE sheets is at the back face of the slab using the sandwich configuration.

- Increasing thickness and number of PTFE sheets decreases fragmentation by up to $90 \%$.

- PTFE sheets placed at the front face did not diminish the blast wave pressure.

- PTFE should be used for blast fragmentation protection purposes only and not in the structural design.

- PTFE sheets can be added to new structures or used to protect existing structures.

- Experimental testing should be conducted to verify the results.

\section{References}

1. UFC-3-340-02 Structures to Resist the Effects of Accidental Explosions. US Army Corps of Engineers, Naval Facilities Engineering Command, Air Force Civil Engineer Support Agency (2008)

2. M. Von Ramin, A. Stolz, Chem. Eng. Trans. 48, 85-90 (2016)

3. X. Lin, Y. X. Zhang, Proceedings of The International Conference on Computational Methods 2, 86-93 (2015)

4. Y. S. Tai, T. L. Chu, H. T. Hu, J. Y. Wu, Theor. Appl. Fract. Mec. 56, 140-147 (2011)

5. J. Weerheijm, H. S. Lim, Proceedings of FraMCoS-6 Conference, (2007)

6. R. O. Ebewele, Polymer Science and Technology (CRC Press, New York, 2000).

7. C.A. Sperati, H. W. StarkweatherJr, Fluorine-containing polymers. II. Polytetrafluoroethylene, 465-495 (Springer-Verlag Berlin Heidelberg, 1961)

8. G. F. Kinney, K. J. Graham, Explosive Shocks in Air (Springer-Verlag Berlin Heidelberg, New York, 1985)

9. J. M. Biggs, Introduction to Structural Dynamics (McGraw-Hill, 1964)

10. P.H. Bischoff, S.H. Perry, Mater. Struct. 24, 425-450 (1991)

11. L.J. Malvar, C.A. Ross, ACI Mater. J. 95, 735-739 (1998)

12. Century Dynamics Company, Inc. AUTODYN Interactive Non-Linear Dynamic Analysis software. Theory Manual, (2005) 